\title{
Reativar a feitiçaria e outras receitas de resistência - pensando com Isabelle Stengers
}

[ Reclaiming witchcraft and other recipes of resistance

- thinking with Isabelle Stengers

\section{Renato Sztutman ${ }^{\mathrm{I}}$}

Versão ligeiramente ampliada e revista de minha apresentação na Mesa "Feitiçarias contrapolíticas, contrafeitiçarias políticas", realizada em I9 de maio de 2017 na VI ReACT. Nessa ocasião, tivemos a oportunidade de falar na presença de Starhawk que, dois dias antes, depois de sua conferência, havia introduzido os participantes da Reunião à sua spiral dance. Gostaria de agradecer aos organizadores da VI ReACT, em especial a Stelio Marras e a Jamille Pinheiro Dias, pela forte interlocução e incentivo. Gostaria também de agradecer a Marina Vanzolini, Clara Flaksman e Jean Tible, que compuseram a mesa, bem como a Peter Skafish, por seus comentários instigantes.

\begin{abstract}
RESUMO - Este ensaio busca explorar os sentidos de reclaim - cuja tradução oscilará entre "reativação" e "retomada" - do modo como figura em textos de envergadura mais política da filósofa da ciência Isabelle Stengers. Num diálogo constante com a escritora e ativista neopagã Starhawk, Stengers discute as possibilidades de reativar ou retomar certas práticas marginalizadas e desqualificadas pelo mundo moderno-capitalista - como a magia e a feitiçaria - vendo aí modalidades de resistência política e possibilidades de recuperação de um "comum". O foco será lançado em dois livros de Stengers - La sorcellerie capitaliste (com Philippe Pignarre) e Au temps des catastrophes - nos quais são tematizadas receitas de resistência, que exigem práticas de "desenfeitiçamento", bem como um alinhamento com Gaia. PALAVRASCHAVE - Isabelle Stengers; reclaim; resistência; ciência e magia; feitiçaria do capitalismo;
\end{abstract}

intrusão de Gaia. • ABSTRACT · This essay aims to explore the meanings of the concept of reclaim, as it appears in some political writings of Isabelle Stengers, philosopher of science. In her constant dialogue with Starhawk, neopagan activist and writer, Stengers discusses the possibilities of reclaiming certain practices - such as magic and witchcraft - which were marginalized and disqualified by the modern-capitalist world, recognizing among them modalities of political resistance and possibilities for the recovery of a "common wealth". This essay will focus on two books of Stengers - La Sorcellerie capitaliste (with Philippe Pignarre) and Au Temps des catastrophes - which thematize recipes of resistence, recipes that provides ways to break the spells and to produce alignments with Gaia. · KEYWORDS - Isabelle Stengers; reclaim; resistence; science and magic; capitalist sorcery; intrusion of Gaia.

Recebido em I8 de dezembro de 2017

Aprovado em 4 de março de 2018

SZTUTMAN, Renato. Reativar a feitiçaria e outras receitas de resistência - pensando com Isabelle Stengers. Revista do Instituto de Estudos Brasileiros, Brasil, n. 69, p. 338-360, abr. 2018.

DOI: http://dx.doi.org/Io.II606/issn.23I6-90IX.voi69p338-360

I Universidade de São Paulo (USP, São Paulo, SP, Brasil). 
Eu vou perguntar para os gerentes, os governadores, os ministros, os vereadores, o governo dos Estados Unidos, Inglaterra, Japão - todos grandes gerentes... Eu vou perguntar a eles $o$ que eles pretendem fazer com a nossa Terra. Eles estão mexendo com pessoas, com a Terra,

com a vida, como se fossem as empresas deles. Nós não temos nada a ver com a loucura deles. Mas eles não são intocáveis... Vamos entrar nos sonhos deles. Junto com a Terra e o universo, nós vamos apontar a loucura. Nós não podemos ficar quietos... Vamos fazer uma rede de pajelança, de magia, vamos fazer confusão no cérebro deles.

(Ailton Krenak, I989)

This is our world now... the world of the electron and the switch, the beauty of the baud. We make use of a service already existing without paying for what could be dirt-cheap if it wasn't run by profiteering gluttons, and you call us criminals. We explore... and you call us criminals. We seek after knowledge... and you call us criminals. We exist without skin color, without nationality, without religious bias... and you call us criminals. You build atomic bombs, you wage wars, you murder, cheat, and lie to us and try to make us believe it's for our own good, yet we're the criminals.

(Manifesto Hacker, I986)

Num diálogo constante com a escritora e ativista neopagã Starhawk, Isabelle Stengers discute as possibilidades de reclaim - que traduziremos aqui ora como "reativar", ora como "retomar" (ver abaixo) - certas práticas marginalizadas e desqualificadas pelo mundo moderno-capitalista, como a magia e a feitiçaria, vendo aí modalidades de resistência política e possibilidades de recuperação de um "comum". Filósofa da ciência, Stengers atenta para o processo de afirmação das ciências modernas a partir da obliteração de práticas julgadas equivocadas, irracionais. Tal obliteração jamais poderia ser dissociada da expansão do capitalismo e sua profusão de poderes. Por isso, insiste Stengers, é preciso trazer as ciências para a política, descortinar toda uma cosmopolítica que pode conferir novos sentidos para a aventura da experimentação e da especulação que envolve a ciência e toda forma de pensamento, oferecendo 
um antídoto à economia do conhecimento vigente, que transforma todo saber em mercadoria e destrói as capacidades de pensar e agir em conjunto. Tomando por base textos de envergadura mais política de Stengers, este ensaio buscará refletir sobre os sentidos de tal reclaim. Sem a intenção de oferecer uma exegese propriamente dita dos textos da autora, busco tão somente pensar com ela. "Pensar com”, estabelecer alianças, é, aliás, uma estratégia recorrente em Stengers, que reúne em torno de si uma série de copensadores, dentre eles, Starhawk ${ }^{2}$.

Leio o chamado à resistência de Stengers tendo em mente a ideia da "sociedade contra o Estado", de Pierre Clastres 3 , imaginando que esse conceito indígenaclastriano - que vê no Estado não uma instituição, mas uma força, um perigo de anulação dos possíveis e da multiplicidade - possa ganhar forma no mundo não indígena. Clastres foi, afinal, lido por Gilles Deleuze e Felix Guattari, autores vigorosamente lidos por Stengers. Todos eles buscando um outro sentido para o que chamamos de política, afastando-se de ideias como coerção, representação, unificação. A ideia de um contra-Estado do pensamento, de uma ciência nômade, tão bem desenvolvida em "La machine de guerre: traité de nomadologie"4, reverbera decerto no que Stengers chamou de "proposta cosmopolítica", isto é, fazer o cosmos - o que não é reconhecidamente político, o mundo dos não humanos e das indeterminações - insistir sobre a política, fazer com que a construção do mundo e do que chamamos natureza - isto é, o trabalho mesmo das ciências - seja incluída numa pauta de luta política. Para Stengers, essa insistência dos que não foram convidados para participar das assembleias modernas é eminentemente um ato de resistência, algo que exige desaceleração dos nossos modos de pensar e agir no mundo.

Palavras como feitiçaria, magia e animismo povoam os escritos de Stengers, e são associadas não raro a um sentido de resistência política, uma vez que refletem práticas banidas ou obliteradas no campo tanto das ciências como da política. No entanto, isso que foi banido ou obliterado volta a insistir contra todo processo de unificação ontológica da modernidade. É nessa direção que o pensamento de Stengers se encontra com as práticas das bruxas neopagãs norte-americanas e, mais especificamente, com a Reclaiming Tradition Witchcraft ${ }^{6}$, organização de viés marcadamente feminista (ou ecofeminista) fundada em I980 por Diana Baker e Starhawk, sob o intuito de juntar espiritualidade e política numa era marcada

2 Lanço mão aqui da fórmula de que ela mesma fez uso em seu livro sobre o filósofo e matemático Alfred $\mathrm{N}$. Whitehead, com quem lhe foi possível elaborar uma abordagem pragmática para os estudos das ciências, recusando a tal "bifurcação da natureza", que opõe gravemente fatos e valores. STENGERS, Isabelle. Penser avec Whiteahead: une libre et sauvage création de concepts. Paris: Seuil, 2002.

3 CLASTRES, Pierre. La societe contre l'état: recherches d'anthropologie politique. Paris: Seuil, I974.

4 DELEUZE, Gilles; GUATTARI, Félix. La machine de guerre: traité de nomadologie. In: DELEUZE, Gilles; GUATTARI, Félix. Mille plateaux: capitalisme et schizophrénie II. Paris: Eds. de Minuit, I980.

5 STENGERS, Isabelle. La proposition cosmopolitique. In: LOLIVE, Jacques; SOUBEYRAN, Olivier (Ed.). L'émergence des cosmopolitiques. Paris: La Découverte, 2007.

6 A Reclaiming Tradition, comunidade de pessoas e organização religiosa sem fins lucrativos, possui um site: http://www.reclaiming.org/. Acesso em: 4 dez. 2018. 
pela ameaça de uma guerra nuclear de escala mundial. A Reclaiming Tradition é decerto um esforço de exercer esta insistência do cosmos sobre a política, conectando a religião e a magia da Deusa (concebida como força vital imanente) a atos de desobediência civil, realizados em manifestações públicas e dirigidos sobretudo contra a militarização e os grandes acordos econômicos que pautam a globalização capitalística. É diante deste cenário que o ato ou atitude de reclaim torna-se uma tópica crucial da proposta cosmopolítica de Stengers.

O termo em inglês reclaim é de difícil tradução, abrangendo um vasto campo semântico, que incluiria o sentido de reapropriar, reconquistar, reafirmar, entre outros. Jamille Pinheiro Dias optou acertadamente por traduzir reclaim por "reativar". Em uma nota de tradução a "Reclaiming animism", ela escreve:

\begin{abstract}
Decidimos pela tradução do verbo to reclaim como "reativar" a fim de abarcar o potencial terapêutico e político da ideia aqui proposta. Entretanto, nenhuma opção bastará em si como satisfatória. Fica o leitor advertido, primeiramente, de que a história do termo passa pela ligação entre magia e espiritualidade e transformação social e política; e, em segundo lugar, de que o "reativar" em jogo diz respeito não a um gesto nostálgico de repetição do passado, mas a ações e práticas situadas, norteadas pelo empirismo e pelo pragmatismo?.
\end{abstract}

No texto referido, Stengers dialoga com a obra do filósofo, ecólogo e artista performático David Abram, que propõe recuperar a ideia de animismo inspirado em cosmologias indígenas e suas relações com os mundos "mais que humanos", marcados por aspectos metamórficos. Stengers contesta a ideia de que práticas animistas estariam confinadas a regimes ontológicos específicos, podendo ser justamente reativadas por práticas modernas. Isso não significaria resgatar algo do passado nem se apropriar de algo inteiramente exógeno, mas sinalizaria uma possibilidade de criação e resistência.

Em suma, Stengers leva a sério a operação da Reclaim Tradition Witchcraft, indo além do contexto de atuação de Starhawk e da tradição europeia (wicca) por ela reativada. O problema central da obra de Stengers talvez seja o de como fazer com que as ciências modernas se conectem com práticas tidas como marginais e, então, reativem aspectos experimentais, especulativos, criativos e combativos que lhes teriam sido tolhidos. Nessa reativação - que poderia também ser dita retomada

7 STENGERS, Isabelle. Reativar o animismo. Tradução Jamille Pinheiro Dias. Belo Horizonte: Chão de Feira, 20I7, p. 8. (Caderno de Leituras n. 62). 
(o que nos conectaria com as lutas indígenas pela terra ${ }^{8}$ - reside, portanto, um ato de resistência. Resistência que não significa, como sugeriu Zourabichvilli em sua leitura de Deleuze, reação ou denúncia, mas sim modo de afirmar uma existência, criar novos possíveis9. Resistência como modo de recusar a captura pelo Estado e pelo regime de subjetividade capitalista, recusar a supressão de um "comum".

Nas páginas que seguem, pretendo examinar o entrelaçamento entre as ideias de reativação (ou retomada) e de resistência política no pensamento de Stengers, tomando como foco dois livros de envergadura claramente política: La sorcellerie capitaliste: pratiques de désenvoûtement ${ }^{\mathrm{I0}}$, de 2005 , e Au temps des catastrophes: resister à la barbarie qui vient ${ }^{\mathrm{II}}$, 2009. No primeiro livro, inspirados nos levantes antiglobalização de Seattle, em I999, Philippe Pignarre e Isabelle Stengers refletem sobre como "habitar territórios devastados pelo capitalismo e pela modernidade"г2. Para eles, é preciso reativar as "técnicas de desenfeitiçamento" capazes de nos proteger do capitalismo - definido aqui como um "sistema feiticeiro sem feiticeiros". Já em Au temps des catastrophes, escrito quatro anos depois, agora sob o impacto das controvérsias sobre os organismos geneticamente modificados e sobre a crise climática e ambiental, Stengers discorre sobre o que ela batiza de "intrusão de Gaia", a "terra viva" que se volta furiosamente contra seus habitantes, alertando para a necessidade de refazer, ou melhor, reativar nossos vínculos com a Terra, que é também uma maneira de restabelecer um "comum".

Ambos os livros tomam politicamente a imbricação entre ciência e política, isto é, evidenciam o que há de político no fazer ciência (fazer fatos e mundos), incitando portanto toda uma cosmopolítica. Tanto a ideia de "desenfeitiçamento" (desenvoûtement, no original) como a de "intrusão" obrigam a pensar receitas de resistência, que passam forçosamente por agenciamentos e conexões entre modos

8 O sentido das "retomadas" de terras - como o são chamadas pelos povos indígenas da atualidade - não se resume ao ato de reaver um pedaço de terra, uma ocupação antiga ou "tradicional", mas todo um modo de existência, e isso muitas vezes pressupõe a reativação de certas práticas ditas mágicas, como o xamanismo, os encantamentos, a oniromancia. Referindo-se aos Tupinambá da Serra do Padeiro, Marcio Goldman escreve que suas retomadas "devem ser entendidas literalmente no sentido proposto por Stengers para a noção de reclaim: não simplesmente lamentar o que se perdeu na nostalgia de um retorno a um tempo passado, mas sim recuperar e conquistar ao mesmo tempo". GOLDMAN, Marcio. "Quinhentos anos de contato": por uma teoria etnográfica da (contra)mestiçagem”. Mana v. 2I, n. 3, 20I5. Desenvolvi essa conexão entre o reclaim stengersiano e os recentes movimentos indígenas de retomadas de terras no artigo: SZTUTMAN, Renato. Retomar a Terra, ou como resistir no Antropoceno - projeto Antropocenas. Buala - Plataforma que atua sobre questões pós-coloniais nas áreas da cultura, comunicação, arte e educação. Disponível em: <www.buala.org/ pt/a-ler/retomar-a-terra-ou-como-resistir-no-antropoceno-projeto-antropocenas 〉. Acesso em: 28 ago. 2017.

9 ZOURABICHVILLI, François. Deleuze e o possível (sobre o involuntarismo na política). In: AlLIEz, É. (Org.). Gilles Deleuze: uma vida filosófica. São Paulo: Ed. 34, 2000.

Io PIGNARRE, Philippe; STENGERS, Isabelle. La sorcellerie capitaliste: pratiques de désenvoûtement. Paris: La Découverte, 2005.

II STENGERS, Isabelle. Au temps des catastrophes: resister à la barbarie qui vient. Paris: La Découverte, 2009.

I2 PIGNARRE, Philippe; STENGERS, Isabelle, op. cit., p. I85. 
de existência heterogêneos. Para resistir, seria preciso desenfeitiçar (o que não deixa de ser também tornar-se feiticeiro, praticante da magia, arte da imanência) e aliar-se com Gaia (essa curiosa "terra viva”, figura transcendente que nos impele a pensar meios de contratranscendência). Seria preciso, enfim, reativar vínculos julgados perdidos ou inexistentes - com deuses e espíritos, mas também com a Terra. Receita é, aliás, mais um termo no qual Pignarre e Stengers insistem. Eles referem-se a receitas de empoderamento, sempre minoritárias - jamais teorias que justificam, porém meios de explorar as possibilidades de um acontecimento. "Receitas feiticeiras", que ressaltam um trabalho de experimentação ativa, sempre aberto ao imponderável e ao imprevisível.

\section{A magia das palavras}

O simples fato de pronunciar palavras como magia, feitiçaria e animismo, diria Stengers, não estaria livre de consequências. No posfácio à edição francesa de Dreaming the dark, de Starhawk, Stengers afirma: "falar de magia não é redutível a uma metáfora, pois o que conta é a maneira pela qual as palavras agem”³. Eis uma aposta no poder transformador da palavra, e isso requer ir além da ideia mais tradicional de metáfora, que separa referência e sentido. Em outro texto, Stengers escreve: "sabemos também que a linguagem não é uma propriedade do homem, um simples veículo prático para transmitir a informação: as palavras nos fazem pensar e sentir"I4. Que seriam conceitos, proposições para Stengers senão palavras em ação? Não haveria, assim, ideias etéreas, imateriais. Seguindo a leitura que Whitehead faz de $O$ banquete, de Platão, ela salienta que as ideias são "coisas que atraem eroticamente a alma humana - ou, poderíamos dizer, aquelas coisas que ‘animam' os humanos”'5. Escrever seria, assim, conceder ao texto uma “animação própria”, um "poder anímico”. E ela declara: "minha experiência de escrever é uma experiência animista, atestando um domínio de um mundo 'mais que humano"”.

Stengers cita então Starhawk:

A magia é uma palavra que causa mal-estar nas pessoas. E eu a utilizo deliberadamente, pois as palavras com que nos sentimos bem, as palavras que soam aceitáveis, racionais, científicas e intelectualmente confiáveis o são precisamente porque fazem parte da língua do distanciamento ${ }^{\mathrm{IT}}$.

Com Starhawk, Stengers aposta numa língua da participação. Usar

I3 STENGERS, Isabelle. Postface à l'édition française. In: STARHAWK. Rêver l'obscure: femmes, magie et politique. Paris: Les Empêcheurs de penser en ronde/Le Seuil, 2003, p. 3I8.

I4 Idem. L'hypnose entre magie et science. Paris: Les Empêcheurs de penser en rond/Seuil, 2002, p. I37.

I5 Idem. Reativar o animismo, op. cit., p. Io.

I6 Ibidem, p. II.

I7 Idem. Postface à l'édition française, op. cit., p. 3I8. 
deliberadamente termos como magia, feitiçaria e animismo seria insistir numa desterritorialização, num devir minoritário no sentido atribuído por Deleuze e

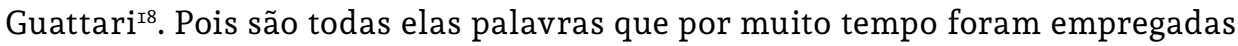
para desqualificar práticas não cristãs e não científicas. Por outro lado, conceitos filosóficos como Logos, Esclarecimento, Razão foram muitas vezes usados para legitimar a colonização, para manter aceso o refrão (o ritornello) da modernidade, qual seja, "nós sabemos, eles creem”. Refrão que Stengers não cansa de subverter.

Stengers reativa palavras como animismo, magia e feitiçaria como um ato de resistência. Para ela, afastando-se da tendência de "dividir e classificar", que estaria presente, por exemplo, no trabalho de alguns antropólogos, todos os povos cultivariam alguma maneira de animismo. Histórias da magia, essa arte da eficácia, e da ciência cruzam-se a todo o momento, prevalecendo porém a "narrativa épica" de que a segunda subsume a primeira, uma vez que somente ela poderia deter verdadeiramente a racionalidade. Stengers pensa a feitiçaria ao modo do pharmakon - a um só tempo veneno e remédio. Se as palavras têm mesmo força, se são espécies de pharmakon, nomear a feitiçaria ou a magia, nomear-se feiticeiro ou animista pode se converter num ato de conjuração, resistência a toda essa história agarrada a uma ideia de progresso a um só tempo da Razão e da técnica. "A fumaça das bruxas queimadas ainda paira nas nossas narinas" - eis o refrão de Starhawk que Stengers insiste em repetir. A história das bruxas queimadas é, com efeito, a história do triunfo da modernidade cristã e do próprio capitalismo. Nomear a feitiçaria, a magia ou o animismo é, portanto, reativar - retomar ou simplesmente ativar - a feitiçaria, a magia ou o animismo. Não se trata de recuperar um passado ou se apropriar de algo inteiramente outro, mas sim de produzir agenciamentos, novas conexões.

Stengers fala/escreve de um lugar específico - como filósofa, mais especificamente filósofa das ciências. "Trata-se de um imperativo moral que confere outro significado à minha decisão de ficar do lado ao qual pertenço. De fato, há um trabalho considerável a ser feito deste lado"ז. A este trabalho a ser feito “deste lado", que destoa do trabalho de antropólogos que estudam outros povos de maneira menos ou mais reflexiva, ela associa justamente a tarefa de reativar/retomar (reclaim) práticas que eram julgadas erradicadas, perdidas, equivocadas. Quando Stengers diz "reativar o animismo" ela se refere à possibilidade de transformar as práticas modernas. É então que define o animismo não como uma ontologia predominante em tal ou tal lugar, mas como "agenciamentos que geram transformações metamórficas em nossa capacidade de afetar e sermos afetados - e também de sentir, pensar e imaginar"º. Para Stengers, é preciso descolonizar as ciências modernas, colocá-las em conexão - parcial que seja, como adverte Strathern ${ }^{2 \mathrm{I}}$ - com outras práticas. E tais conexões conduziriam ao que ela chamou de um "anarquismo ecológico", trânsito por entre meios heterogêneos,

I9 STENGERS, Isabelle. Reativar o animismo, op. cit., p. 3.

20 Ibidem, p. I6.

2I STRATHERN, Marilyn. Partial connections. Lanham: AltaMira Press, I99I. 
como a arte, a ciência e a filosofia; algo capaz de conectar a Virgem Maria ao Neutrino do laboratório, estes não humanos que nos fazem agir e pensar ${ }^{22}$.

A defesa do caráter experimental e especulativo das ciências implicaria, em Stengers, uma abertura ao Fora (mais que a um passado), esta reativação de dimensões esquecidas ou recalcadas. Química de formação, ela busca na alquimia a arte das consequências nublada pelas ciências modernas ${ }^{23}$. Debruçada sobre a vontade de fazer ciência da Psicanálise de Freud, ela investiga o momento decisivo de ruptura com as práticas de hipnose, relegadas ao plano da imaginação e da sugestão ${ }^{24}$. Tanto a Química como a Psicanálise precisaram expulsar a magia para fazer-se científicas, mas eis que elas acabam por se esquecer de suas fundações experimentais e especulativas. Elas se deixariam aprisionar por um caráter épico - conquista de certa verdade por meio da conjuração das más razões - deixando de lado o caráter de aventura, essa abertura ao indeterminado, algo que Stengers coloca em primeiro plano ao buscar repensar essa história científica.

Stengers conclui seu livro sobre a hipnose, L'hypnose entre magie et science ${ }^{25}$, de 2002, com uma reflexão sobre técnicas terapêuticas alternativas, aproximando a experiência da clínica em etnopsiquiatria de Tobie Nathan com a do reclaim das bruxas neopagãs. Como Starhawk, Nathan é um copensador crucial para Stengers. Sua proposta de clínica etnopsiquiátrica visa justamente restituir o lugar de outras práticas terapêuticas no tratamento de imigrantes africanos e magrebinos na França. Se a medicina moderna afirmou-se com a perseguição aos "charlatões" os que curam por "más razões" -, é preciso agora, num tempo de intensa e difícil coexistência, fazer conversar diferentes práticas, reconhecendo nelas regimes de eficácia e veridicção. A etnopsiquiatria é tomada como um exemplo crucial em sua discussão sobre a paisagem problemática das ciências humanas no último tomo de Cosmopolitiques $^{26}$. Pois os etnopsiquiatras não visam apenas etnografar situações de sofrimento e infortúnio, eles buscam sobretudo construir pontes entre diferentes terapêuticas; nesse sentido, admitem reativar no interior da medicina e da psiquiatria algo que teria há muito sido expulso dela ou que sempre lhe escapou, isto é, a magia, a ideia de que não estamos sozinhos no mundo, e isso implica forçosamente um risco, uma aventura, uma indeterminação.

Como a etnopsiquiatria, o movimento das bruxas neopagãs implica a afirmação de práticas minoritárias, que escapam do modelo do sujeito psicológico e da ideia de emancipação. Em ambos os casos, sugere Stengers, estamos diante de um pensamento "pharmakológico", marcado pela incerteza, pela indeterminação. Se a Ciência hegemônica esvazia a potência do pharmakon, buscando estabilidades e

22 STENGERS, Isabelle. La Vierge et le Neutrino: les scientifiques dans la tourmente. Paris: La Découverte, 2006.

23 Ver: BENSAUDE-VINCENT, Bernadette; STENGERS, Isabelle. Histoire de la chimie. Paris: La Découverte, I993; PRIGOGINE, Ilya; STENGERS, Isabelle. La nouvelle alliance: métamorphose de la science. Paris: Gallimard, I979.

24 Ver: CHERTOK, Léon; STENGERS, Isabelle. L'hypnose: blessure narcisique. Paris: Les Empêcheurs de penser en rond, I999; STENGERS, Isabelle. L'hypnose entre magie et science, op. cit.

25 STENGERS, Isabelle. L'hypnose entre magie et science, op. cit.

26 Idem. Pour en finir avec la tolérance. In: . Cosmopolitiques II. Paris: La Découverte, I997. 
um poder de julgamento, as práticas minoritárias operam uma arte farmacológica dos devires, sabendo que toda linha de vida pode converter-se em linha de morte. Etnopsiquiatras sabem que um diagnóstico pode ser compreendido como um ato de divinação, no qual devem ser examinados devires, "cuja possibilidade assombra o que é” ${ }^{27}$. Em consonância com práticas não modernas, a terapêutica passa a ser pensada de modo pragmático, como experimentação e não como algo pautado num diagnóstico unívoco.

Com Stengers, em suma, as ciências devem reativar a magia, essa arte da eficácia, tanto porque jamais houve ciência sem magia - sem animação do mundo, sem fatos que são feitos, sem "fatiches". No entanto, como admitiria o próprio Bruno Latour, esse "fatichismo" manteve-se sempre como face oficiosa das ciências modernas, algo que não poderia romper as barreiras dos laboratórios e seus recintos ${ }^{28}$. sentido que é preciso politizar as ciências: abrir as controvérsias, evidenciando como fatos são feitos, e isso implica que os cientistas devam explicitar seus vínculos, pensar suas práticas como indissociáveis de um "meio"; isto é o que Stengers chamou de uma “ecologia das práticas”29.

\section{DESENFEITIÇAR, ARTE DA IMANÊNCIA}

Em La sorcellerie capitaliste, Philippe Pignarre (editor da coleção Les Empêcheurs de Penser en Ronde) e Isabelle Stengers declaram-se herdeiros de Marx; não de um marxismo que busca estabelecer as leis da história, mas da tradição de luta contra o capitalismo. Com a ideia de "fetichismo da mercadoria", desenvolvida em $O$ capital, Marx evidenciou muito bem como o capitalismo é mestre de produzir ilusões, fazendo com que coisas tomem o lugar de pessoas. Trata-se, todavia, com Stengers e Pignarre, de ir além de Marx, levando às últimas consequências essa ideia da feitiçaria do capitalismo, uma feitiçaria que se exerce contra as feiticeiras, estas que permanecem ausentes de $O$ capital.

Pignarre e Stengers inspiram-se na associação estabelecida por Starhawk, inspirada pelo livro Marxism e witchcraft, de David Kubrin, entre a origem do capitalismo - que Marx associa à destruição da propriedade comum da terra (direitos consuetudinários) pelos cercamentos (enclosures) na Inglaterra do século XVIII - e a erradicação derradeira das práticas de bruxaria, associadas ao universo feminino ${ }^{30}$. Consideremos mais a fundo essa hipótese e também a maneira como ela ganha desenvolvimento no trabalho da historiadora feminista Silvia Federici, ainda que este não tenha sido incorporado por Pignarre e Stengers. Em Calibã e a bruxa, Federici demonstra haver uma relação direta entre a caça às bruxas durante

27 Idem. L'hypnose entre magie et science, op. cit., p. I57.

28 Ver, em especial, LATOUR, Bruno. Petite refléxion sur le culte moderne des dieux faitiches. Paris: Les Empêcheurs de penser en rond, I993.

29 STENGERS, Isabelle. Cosmopolitiques I. Paris: Éditions la Découverte, I997; Cosmopolitiques II. Paris: La Découverte, I997.

30 STARHAWK. Dreaming the dark: magic, sex, and politics. Boston: Beacon Press, I982. 
os séculos XVI e XVII e a acumulação primitiva de capital, e isto toca numa questão fundamental de gênero. Para Federici, a exploração das mulheres, o controle de seu poder reprodutivo é algo inerente ao capitalismo, não devendo ser universalizado, como sugeriu, entre outros, Strathern em seu estudo sobre as relações de gênero na Melanésia ${ }^{3 \text {. }}$ Os cercamentos da terra seriam seguidos por cercamentos de conhecimentos, por exemplo, a perseguição de curandeiras por uma nova classe de doutores. "A substituição da bruxa e da curandeira popular pelo doutor", escreve Federici, "levanta a questão sobre o papel que o surgimento da ciência moderna e da visão científica do mundo tiveram na ascensão e queda da caça às bruxas" ${ }^{32}$. Federici situa a caça às bruxas, esse movimento de demonização e segregação, como um fator fundamental para a compreensão não apenas da acumulação primitiva do capital, mas também da gênese de um biopoder, que Foucault associava ao declínio do poder soberano no século XVIII.

Inspirados pela tese da associação entre caça às bruxas e origem do capitalismo, e fortemente interessados no feminismo como luta minoritária (veja-se passagens reveladoras sobre o feminismo negro), Pignarre e Stengers sugerem que o capitalismo não teria acabado com a feitiçaria, mas sim com os feiticeiros. Tudo se passa como se o capitalismo tivesse capturado toda a feitiçaria existente no mundo, tornando-se um "sistema feiticeiro sem feiticeiros". É nesse sentido que sua operação é a da "captura", conceito mais uma vez deleuze-guattariano, que implica a subsunção de uma força ou fluxo a um aparelho centralizador, sobrecodificador. No entanto, essa captura resulta na produção de um poder que entorpece as pessoas, que não as impede de ver o seu rosto. A pretensa invencibilidade do capitalismo estaria refletida na sua capacidade de surpreender oponentes, de tirar lucro de qualquer oportunidade, tirar proveito de qualquer desatenção, de produzir, enfim, a impotência nas pessoas.

A ideia de uma feitiçaria que "tira a força" das pessoas ressoa também na definição que Jeanne Favret-Saada encontra para a feitiçaria segundo os habitantes de uma comunidade rural no interior da França33. A feitiçaria é descrita pelos interlocutores de Favret-Saada como força anormal que esvazia a pessoa e que, portanto, exige a intervenção de um mago especial. A necessidade de desenfeitiçar seria ali mais importante do que a de revelar o agressor. Pignarre e Stengers distinguem "desenfeitiçar" - proteger-se - da ideia de "revelar", "desvelar", "desalienar", desvendar enfim a Verdade. Reclamar o desenfeitiçamento implica sobretudo assumir que somos vulneráveis. Assim denomina Claudia Andujar sua coletânea de fotografias, na qual muitas das imagens estão engajadas em captar o sentido do xamanismo yanomami: "vulnerabilidade do ser"34. Não estamos sozinhos no mundo, sabem bem os Yanomami. Há muitos agentes, visíveis e invisíveis, contra os quais é preciso

3I STRATHERN, Marilyn. The gender of the gift: problems with women and problems with society in Melanesia.

Berkeley: University of California Press, I988.

32 FEDERICI, Silvia. Calibã e a bruxa: mulheres, corpo e acumulação primitiva. São Paulo: Ed. Elefante, 20I7, p. 364 .

33 FAVRET-SAADA, Jeanne. Les mots, la mort, les sorts: la sorcellerie dans le Bocage. Paris: Gallimard, I977. Ver também, da autora, Désorceler. Paris: Ed. de l'Olivier, 2009.

34 ANDUJAR, Claudia. A vulnerabilidade do ser. São Paulo: Cosac Naify, 2005. 
proteger-se, e isso se dá compondo com eles. Mas sabem também os Yanomami que se desenfeitiçar, proteger-se é saber lançar mão de um feitiço, tornar-se feiticeiro ${ }^{35}$. E eles, mais do que ninguém, sabem que o capitalismo - com suas mercadorias e tecnologias - emana feitiçaria por todos os lados, acarretando efeitos nefastos e patogênicos que somente os xamãs poderiam reverter ${ }^{36}$.

Desenfeitiçar é, tanto nos exemplos de Pignarre e Stengers, como naqueles mais etnográficos oferecidos por Favret-Saada e Kopenawa, proteger-se ou ainda "empoderar-se". É recobrar aquilo que o capitalismo tomou e sobrecodificou, a feitiçaria não como malefício, mas como pharmakon, remédio como veneno. Para falar do desenfeitiçamento, Pignarre e Stengers tomam emprestado outro termo do vocabulário ativista (do feminismo, do movimento negro): empowerment. "Empoderamento" não me parece contudo a melhor tradução, poderíamos talvez pensar em "autodeterminação". De todo modo, quando Stengers e Pignarre se referem a técnicas de empowerment, estão pensando na habilidade de imaginar, de mover-se sem medo, de criar novas lutas, tendo em vista sempre devires minoritários. Eis justamente o tema de um livro como La sorcellerie capitaliste: apostar em uma "política do possível" - quiçá outro nome para a cosmopolítica - contra a "política do provável”, que não cessa de nos amortecer. Esse seria o grande desafio lançado para as esquerdas e um antídoto às armadilhas da direita, antinomia que os autores, seguindo "Les intercesseurs" de Deleuze ${ }^{37}$, recusam-se a abolir.

Não se trata de metáfora, vale insistir, quando Pignarre e Stengers falam em luta (anticapitalista) como contrafeitiçaria ou desenfeitiçamento. Esses seriam dispositivos propriamente pragmáticos. O capitalismo nos enfraquece, pois mata os possíveis e mesmo a política, nos desobriga a pensar, nos entorpece e nos chantageia com suas alternativas infernais. Por exemplo, quando estabelece que ou a Europa deve aceitar os organismos geneticamente modificados ou perderá a competitividade mundial, seus pesquisadores migrarão para os Estados Unidos, sucumbir-se-á a uma imensa fome. Poderíamos com facilidade proliferar exemplos, tendo como referência a realidade brasileira mais recente: ou a reforma da previdência ou a falência do Estado; ou Belo Monte ou a crise da energia; ou o freio à imigração ou o colapso social; ou a indústria farmacêutica ou o fim do financiamento das pesquisas. Para evitar esse ou/ou que nos enfraquece, não basta denunciar, mas sim lutar por possíveis, forças que passam pelo meio, que se convertem em linhas de fuga. Contra as alternativas infernais, as lutas anticapitalistas e a insistência de fazer as ciências

35 Não estou aqui fazendo jus à importante etnografia de Bruce Albert - Temps du sang, temps des cendres: répresentation de la maladie, système rituel et espace politique chez les Yanomami du Sud-Est (Amazonie Brésilienne). Thèse de doctorat. Paris, Laboratoire d'Ethnologie et de Sociologie Comparative, I985 -, que distingue entre os Yanomami modalidades de feitiço entre grupos relativamente próximos e o xamanismo agressivo, exercido entre grupos relativamente distantes e potencialmente letal.

36 Esse é, por exemplo, um dos aspectos do discurso cosmopolítico de Davi Kopenawa em: KOPENAWA, Davi; ALBERT, Bruce. A queda do céu: palavras de um xamã yanomami. São Paulo: Companhia das Letras, 2015.

37 DELEUZE, Gilles. Les intercesseurs. In: Pourparlers. Paris: Ed. de Minuit, I990. 
entrarem na política em nome de uma consciência mais apurada e, portanto, de um movimento de desaceleração ${ }^{38}$.

Pignarre e Stengers recusam-se a oferecer um programa, declarando-se "lançadores de sondas", versados na arte de "prestar atenção". Não se trata para eles de encontrar saídas transcendentes, mas sim soluções locais e criativas. É nesse sentido que se declaram herdeiros de Marx, mas também (ou sobretudo) da batalha de Seattle, que se configurou contra a reunião da Organização Mundial do Comércio em I999, ápice do processo de globalização do capital financeiro. Seattle teria sinalizado a produção de uma nova existência, conectando táticas de ativismo e ação direta de diferentes origens: ecologistas, anarquistas, operários, estudantes, pacifistas, humanistas, entre outros tantos. Ao lado de outros acontecimentos - como a greve geral na França em I995 e a eclosão da guerrilha zapatista em I994 - Seattle marcaria o fim dos "anos de inverno", como os chamava Félix Guattari, uma vez que restabeleceria a confiança de que "um outro mundo é possível". Esse grito poderia ser pensado como o próprio do desenfeitiçamento, da contrafeitiçaria. Não se trata de tomada de consciência, mas da necessidade de pensar novas formas de ação política, para além da gramática e dos agentes das esquerdas tradicionais.

Não por acaso, as bruxas ativistas e, mais especificamente, Starhawk, aparecem no livro de Pignarre e Stengers como personagens cruciais. Elas se nomeiam feiticeiras, reativando aquilo que a história de perseguições religiosas, de misoginia, dos cercamentos (enclosures) tentou suprimir por completo, isto é, uma "espiritualidade enraizada na Natureza, no erotismo e na terra" 39 . Uma espiritualidade que se expressa pela reabilitação do ritual como política, um "poder de dentro", nos termos de Starhawk, que pode ser vinculado a movimentos de liberação política, movimentos contra o "poder sobre", exercido pelo Estado, pelo sistema mundial e pelas grandes religiões. As feiticeiras ativistas e a luta que instanciam se contrapõem ao que os autores chamam de "mãozinhas", representantes desse "poder sobre" a quem cumpre a função de dizer o que é melhor para todos.

Starhawk e as bruxas neopagãs buscam reativar no seio da modernidade uma tradição europeia, a tradição wicca, desvencilhando, todavia, sua atitude do sentido da ancestralidade. Starhawk se pergunta: "nosso título de bruxas depende de nossa ancestralidade? Se sim, eu como judia teria mais direito de clamar pela deusa irlandesa Brigid do que pela Mulher Aranha dos Pueblo?"40. Não se trata justamente nem de ancestralidade wicca, nem de tomar algo dos outros - dos povos indígenas, por exemplo. Não se trata nem de resgate, nem de apropriação cultural - dois fantasmas que nos rondam nos dias de hoje -, mas de criatividade, de novos rituais. Como escreve Émilie Hache, Starhawk pensa politicamente a espiritualidade - religião profana, pagã, religião da imanência -, isto é, como forma de produção

38 Sobre a ideia de “desaceleração", ver: STENGERS, Isabelle. Une autre science est possible! Manifeste pour un relentissement des sciences. Paris: La Découverte, 20I3.

39 STARHAWK. Rêver l'obscure: femmes, magie et politique. Paris: Les Empêcheurs de penser en ronde/Le Seuil, 2003, p. 8.

40 Idem. Webs of power: notes from the global uprising. Gabriola Islands: New Societies Publisher, 2002, p. 202-203. 
de antídotos às religiões universais ou de Estado ${ }^{4 \mathrm{I}}$. Mais importante que um resgate seria a possibilidade de criar novos rituais em espaços abertos - a extática dança em espiral (spiral dance), por exemplo - dotados de força performática e política. É assim que Starhawk conduziu um sem-número desses rituais nas mais diferentes manifestações públicas ligadas a movimentos antiglobalização, por exemplo, a própria batalha de Seattle, conectando táticas de ação direta e ativismos de diferentes vieses - ecologistas, anarquistas, operários, pacifistas, estudantes, entre outros.

Stengers, em outro artigo, frisa o caráter pragmático dessa reativação dessa espiritualidade feiticeira, o que não significa de modo algum recair no ceticismo. A feitiçaria permitiria "habitar zonas de experiência devastada", "restaurar a vida que foi envenenada" ${ }^{2}$. Desenfeitiçar seria, por isso, um modo de minar o sistema capitalista feiticeiro "por dentro". Seria recobrar o que ele tomou para se tornar o que é. É assim, em suma, que em La sorcellerie capitaliste Pignarre e Stengers conectam essa "proposta feiticeira" com uma série de ativismos que buscariam, eles também, desenfeitiçar, criar novos possíveis por meio de novas formas de ação. Contra o sistema "feiticeiro sem feiticeiros" a proliferação incessante de contrafeitiços, que não deixam de ser eles também feitiços. Contra uma feitiçaria transcendente, que não tem corpo nem rosto - inominável portanto (como o Estado, diria Clastres) -, uma proliferação de feiticeiros nomeados, artífices da imanência.

\section{Alinhar-Se Com Gaia, téCniCa de CONTRatransCendênCia}

Lembremos que o reclaim de Starhawk nasceu da ameaça, nos anos I980, na era Reagan, de uma guerra nuclear, que punha em risco todo o planeta. Contra isso, seria preciso retomar a relação com a terra, que está na base do paganismo. É certo que na aurora do século XXI vivenciamos uma nova ameaça de fim do mundo, desta vez pela crise ambiental e climática, esta também provocada pela ação humana. Em Au temps des catastrophes, Stengers nomeia “intrusão de Gaia” essa resposta à expansão predatória do capitalismo, a essa era que poderíamos agora chamar Capitaloceno ${ }^{43}$. Para Stengers,

4I HACHE, Émilie. Starhawk, le rituel et la politique. In: CONGRES MARX INTERNATIONAL V - Section

Etudes Féministes Atelier 9: Féminismes, altermondialisme et utopies - Paris-Sorbonne et Nanterre - 3/6 octobre 2007.

42 STENGERS, Isabelle. Experimenting with refrains: subjectivity and the challenge of escaping modern dualism. Subjectivity, v. 22, n. I, 2008, p. 58.

43 Capitaloceno seria um outro nome do Antropoceno, era em que o "homem" constituiria a força geológica dominante no planeta. Em Au temps des catastrophes, Stengers não emprega uma só vez o termo Antropoceno, decerto por acreditar que o problema resida não na ação do "humano" em geral, mas no desenvolvimento de certa civilização. Com efeito, há toda uma polêmica em torno do termo Antropoceno. Autores têm empregado os mais diferentes nomes para falar do fenômeno da ameaça de certa civilização para a integridade da Terra Capitaloceno, Plantionceno, Chtuluceno, Carbonoceno ou mesmo White Supremacy Scene. Ver, entre outros: MOORE, Jason M. (Ed.). Anthropocene or Capitalocene? Nature, history and the crisis of capitalism. Oakland: PM Press, 20I6; HARAWAY, Donna. Staying with the trouble: making kin in the Chtulucene. Durham: Duke Press, 2016. 
Gaia, essa "terra viva" suscetível, raivosa e "indiferente às razões humanas", irrompe como uma "forma inédita de transcendência"4. Uma forma de transcendência que no entanto se choca com aquela do sistema capitalista e do gênero épico que ele instaura. Gaia é cega a esse gênero épico e a seu ideal de emancipação, que permite que crenças dos outros longínquos sejam insultadas. Contra a transcendência do progresso a outra transcendência, ou melhor, a contratranscendência de Gaia, que exige novamente que "prestemos atenção". Além de desenfeitiçar, agora também é preciso alinhar-se com Gaia para "resistir à barbárie que se aproxima".

Se La sorcellerie capitaliste tinha como grande acontecimento Seattle, esse grande ato de desenfeitiçamento e recriação da política, guiado pelo impedimento da reunião da Organização Mundial do Comércio, Au temps des catastrophes parte das controvérsias sobre o cultivo de sementes transgênicas (organismos geneticamente modificados - OGM) na França, tendo as catástrofes ambientais e as mudanças climáticas como pano de fundo 45 . Isso exige mais uma vez que os cientistas venham ao debate público, abrindo controvérsias e questionando laços entre ciência, Estado e empresas, para enfim politizar as ciências, trazendo a natureza - e seus fatos, "fatiches" - para a política. O acontecimento OGM seria capaz de inserir na política o que estava fora dela; e se ele propicia o enfurecimento de Gaia é porque ela se torna um ator político da maior importância. Stengers recupera a controversa hipótese Gaia de James Lovelock e Lynn Margulis - a Terra como "entidade viva", a atmosfera como criação de microrganismos - tendo em vista o cenário de desastres ambientais e mudanças climáticas, que exige uma politização das ciências. Como evitar uma Nova Orleans planetária, o desastre "natural" produzindo o caos "social" - eis a questão fundamental, que não paramos de prefigurar a cada dia quando lemos os jornais.

Gaia, lembremos, é o nome de uma divindade do panteão grego, a filha de Caos, associada à Terra, marcada pelo espírito vingativo e pela fúria em relação à tirania. O que Stengers denomina "intrusão" de Gaia é uma resposta raivosa à transcendência (e à tirania) produzida pelo capitalismo em seu movimento de expansão predatória. Gaia não seria meramente um outro nome da Terra enquanto recurso a ser explorado: "ela é o nome daquilo que um novo campo científico sinaliza", uma "nova figura da ciência", que não possui um rosto, mas sim "um conjunto complexo emaranhado de modelos e dados" ${ }^{\prime 6}$. Gaia não corresponderia à Deusa da Reclaiming Tradition de Starhawk, ela seria, antes, a contrapartida da feitiçaria do sistema capitalista, nos obrigando a pensar um outro sentido de planetaridade, sem com isso cairmos numa imagem teológica ou epistemológica de unificação; e a tal nova planetaridade seria uma resposta à ideia de um capitalismo globalizado.

44 STENGERS, Isabelle. Au temps des catastrophes..., op. cit., p. 95.

45 Stengers faz referência, mais especificamente, às repercussões do ato, ocorrido em fevereiro de I997, de Alain Juppé, primeiro-ministro da França, de proibir o cultivo de sementes de milho transgênico, algo que seria revogado nove meses depois, com a autorização do cultivo porém seguido de biovigilância.

46 STENGERS, Isabelle. Gaia, the urgency to think (and feel). In: COLÓQUIO INTERNACIONAL OS MIL NOMES DE GAIA: DO ANTROPOCENO À IDADE DA TERRA. Casa de Rui Barbosa, Rio de Janeiro. Departamento de Filosofia/PPGAS Museu Nacional/UFRJ. I5 a I9 set. 20I4. Disponível: <https://osmilnomesdegaia.files. wordpress.com/20I4/II/isabelle-stengers.pdf. Acesso em: 26 ago. 20I7, p. 2. 
Em Au temps des catastrophes vemos uma nova exigência de reativação. Se somos herdeiros da destruição do "bem comum", da perda de laços com a Terra, é preciso reativar vínculos. Para resistir à barbárie que se aproxima é preciso "nomear Gaia”! A questão central passa a ser, então, o que pode recriar esse vínculo, no sentido de "fazer pegar novamente uma planta"47, fazê-la crescer em outro lugar. Ou, para evocar uma imagem da peça didática de Baden Baden sobre o Acordo, de Bertolt Brecht: para evitar a catástrofe um aviador deve entrar em acordo com a tempestade que o ameaça ${ }^{48}$. Gaia seria aqui a tempestade que irrompe, com quem se deve compor - no sentido de alinhar-se - para evitar a catástrofe. Gaia torna-se, assim, um novo refrão contra a grande narrativa épica do progresso e da emancipação, que se pauta pelo valor da inovação a qualquer custo.

Por que retomar a proposição de origem científica, de James Lovelock e Lynn Margulis? Aqui vale a pena retomar o argumento de Latour em Face à Gaïa, de 2005, que atualiza um constante diálogo com Stengers. Latour pergunta-se sobre o que seria esse "novo regime climático" que nos obriga a destronar de uma vez por todas a "religião natural" dos modernos - aquela que toma a "Natureza" como domo - e então buscar uma nova entidade, secular, mundana. Latour toma Lovelock como o Galileu de nossos tempos, extraindo de seus achados consequências metafísicas importantes. Se Galileu inseriu a Terra num universo infinito, promovendo o que Freud chamou de uma "ferida narcísica", Lovelock promoveu um movimento contrário de retorno à Terra, tratando-a como um caso singular. A Terra de Lovelock é um planeta vivo e animado. Com Margulis, Lovelock sugeriu que não se trata, como para os darwinistas, de organismos adaptando-se ao ambiente, mas da produção mesma da Terra pelos organismos, que geram seus próprios ambientes. Não estamos na atmosfera, afinal, “a atmosfera somos nós”, resume Latour ${ }^{4}$. Concepção análoga poderia ser encontrada na mitofísica ameríndia que, segundo Deborah Danowski e Eduardo Viveiros de Castro, professa que antes de o mundo existir havia pessoas; o mundo, assim, nada mais seria que um composto de pessoas, invertendo a ideia de que antes das pessoas já haveria um mundo, pronto para recebê-las ${ }^{50}$. Outra analogia poderia ser reconhecida entre os indígenas australianos estudados por Elizabeth

47 STENGERS, Isabelle. Au temps des catastrophes..., op. cit., p. I38.

48 BRECHT, Bertolt. (I929). A peça didática de Baden Baden sobre o Acordo. In: Teatro completo volume

3. São Paulo: Paz e Terra, I988.

49 LATOUR, Bruno. Face à Gaïa: huit conférences sur le nouveau regime climatique. Paris: La Découverte, 20I5, p. 89.

50 DANOWSKI, Débora; VIVEIROS DE CASTRO, Eduardo. Há mundo por vir? Ensaio sobre medos e fins. São Paulo: ISA; Florianópolis: Cultura e Barbárie, 20I4. 
Povinelli, que recusam a ideia de objetos e paisagens como "coisas indiferentes" 5 . Na geontologia (ou meteorontologia) particular desses povos australianos, os limites entre o vivo e o não vivo, como estipulados pelas ciências modernas, teriam de ser repensados e, portanto, politizados. Voltando a Lovelock e Margulis: a Terra e o clima evoluem junto - coevoluem - com a vida, e o espaço deixa de ser meramente contexto ou extensão (res extensa) para ser coproduzido. Segundo Latour, Lovelock nos obriga a situar ação humana numa grande geo-história, que se contrapõe ao mononaturalismo e à projeção universal do homo economicus. Uma geo-história que poderia resistir ao que Povinelli chama de geontopoder, esse poder de dispor da Terra e controlá-la segundo intenções lucrativas e que só pôde florescer na era de um "liberalismo tardio", associado ao chamado Antropoceno ou Capitaloceno.

Gaia seria um contraponto à ideia de Natureza, esta que definiu a "teologia política" dos modernos. A Natureza seria, assim, resultado da secularização dos nossos conceitos religiosos. É nesse sentido que, para Latour, é preciso uma nova "teologia política", uma nova entidade capaz de convocar os agentes, criar um novo povo - o povo de Gaia, os "terranos" (Earthbound). Latour revisita o velho tema da relação entre política e religião, dessa vez para pensar uma espécie de "apocalipse profilático". Diferentemente da démarche de Starhawk, ele se dirige não a uma espiritualidade imanente, mas ao problema mesmo da transcendência religiosa. Em diálogo com Gunther Anders e com certa tradição escatológica cristã, pergunta-se sobre como viver durante o tempo do apocalipse, o "tempo do fim" - o tempo da bomba atômica, do aquecimento global, este que exigiria uma radical transformação de nossas teologias políticas. Este "apocalipse profilático" seria uma espécie de imunologia, que não deixa todavia de ser uma forma de proteção, de desenfeitiçamento.

Tanto em Latour como em Stengers, Gaia aparece como algo maior que nos obriga a pensar e a agir, uma irrupção de algo que nos transcende. No entanto, poderíamos dizer que Stengers se afasta do tom mais propriamente messiânico de Latour, visto que não está exatamente interessada numa escatologia. Menos do que uma entidade capaz de convocar um "novo povo", Stengers busca um sentido para a planetaridade, que reside antes de tudo no estabelecimento de conexões possíveis entre uma multiplicidade de práticas e lutas. Em vez de um sentimento apocalíptico, a busca de bons encontros e paixões alegres, no sentido spinoziano dessas expressões. Em vez de um “mundo comum", mesmo que provisório, pensar possibilidades de coexistências, de conexões parciais. Trata-se assim de responder à transcendência de Gaia na forma de múltiplas contratranscendências; enfim, de "aprender a experimentar os dispositivos que nos tornam capazes de viver tais provações sem cair na barbárie” ${ }^{2}$.

5I POVINELLI, Elizabeth. Geontologies: a requiem to late liberalism. Durham: Duke Press, 20I6.Como Danowski e Viveiros de Castro, Povinelli debate teses recentes de filósofos associados ao "realismo especulativo", como é o caso de Quentin Meillassoux, para quem é possível à filosofia falar sobre as coisas, sem pressupor a correlação com um sujeito. Essa filosofia contrastaria, contudo, com aquelas de povos ameríndios e australianos, para quem não haveria como pensar o mundo sem sujeitos, ainda que estes desafiem a distinção não apenas entre humano e não humano, mas também entre vivente e não vivente. É nesse sentido que, como insiste Latour, "a atmosfera somos nós", subvertendo o binômio organismo e ambiente, nós e o mundo.

52 STENGERS, Isabelle. Au temps des catastrophes..., op. cit., p. I42. 
As receitas de resistência passariam, tanto em La sorcellerie capitaliste como em Au temps de catastrophes, pela ideia de conexões capazes de barrar a criação de novos cercamentos (enclosures), resistir a capturas do "comum" (o "bem comum", aquilo capaz de "fazer comunidade") sem cair na ideia de um "mundo comum" unívoco. É nesse sentido que ela aposta na figura dos "usuários" - aqueles que se reúnem em torno de um "bem comum", por exemplo, os usuários de drogas, os pacientes soropositivos - em contraste com a dos "utilizadores", que recusam qualquer forma de risco. E também na dos "praticantes" - reunidos por uma causa comum - em contraste com a dos "profissionais especializados", ligados à indústria. O ponto para Stengers é fazer com que cientistas busquem inspiração na figura desses usuários e praticantes, uma vez que precisam inventar modos de resistir aos cercamentos modernos, que impedem o estabelecimento do comum, privatizando-o. Tal seria o problema da nova economia do conhecimento, aquela que minimiza a autonomia dos pesquisadores, cooptando-os para parcerias com indústrias e modos de patenteamento, protegidos pelo Estado para que sejam imediatamente postos em circulação no mercado.

Dialogando com a ideia de "capitalismo cognitivo" de Negri e Hardt, Stengers evidencia que o que se apropria hoje não é mais a força de trabalho, e sim o conhecimento. E segundo ela, diferentemente dos autores, não se trata exatamente de um "saber abstrato" de um "proletariado imaterial", mas de relações, da constituição de comunidades. A questão passa a ser portanto como não deixar que esse conhecimento compartilhado seja capturado. O que os novos cercamentos destroem é uma inteligência coletiva - essa capacidade de pensar e imaginar juntos, de promover conexões -, destroem o que faz comunidade, e não apenas um saber abstrato. Para Stengers, a resposta para tanto não é vislumbrar uma humanidade reunificada, mas sim povoar o mundo com capacidades coletivas capazes de escapar do tal "gênero épico", esse vício ao qual teria sucumbido o conceitual marxista.

Um tema que atravessa tanto La sorcellerie capitaliste como Au temps des catastrophes é o da revolta dos informáticos, o hackerativismo. Stengers vê aí uma revolta organizada, constituída por redes de cooperação ativas. Esses programadores definem-se como commoners vinculados, inventando modos criativos e engenhosos de resistir à captura. Se a informática é mesmo o grande cercamento contemporâneo, operando pelo incessante patenteamento dos algoritmos e suas linguagens, é preciso prestar atenção às respostas que foram se configurando, por exemplo, com a criação de softwares livres, os infiltramentos que culminam na organização de modos de resistência e na recusa da apropriação exclusiva do que se cria. Esses programadores, hackers, tantas vezes acusados de traidores e criminosos, se assemelhariam ao que Deleuze e Guattari denominaram, em Mille plateaux, "nômades": aqueles que traçam uma máquina de guerra, tomando dos impérios as suas armas, aqueles que resistem nas franjas do poder, e não fora delas. Não por acaso, o nascimento da informática está ligado a uma tecnologia de guerra, ao desenvolvimento militar; apropriar-se dela seria traçar uma máquina de guerra nômade, seria inscrever-se numa "nomadologia".

Os cientistas, afirma Stengers, precisam se espelhar nos programadores, aqueles que burlam o império, a indústria, atuam "por dentro" para então se reunirem novamente em torno de um "bem comum". Os cientistas se veriam, assim, obrigados a rever seu papel, sendo chamados a se inserir no debate público para questionar 
o problema dos organismos geneticamente modificados, do patenteamento dos medicamentos, da construção de hidrelétricas, entre tantos outros fóruns que fazem mundos. Apenas conectando-se a outras práticas, movendo-se por esse "anarquismo ecológico", lhes seria possível resistir à captura da economia do conhecimento, traçar uma linha nômade.

Com Stengers, a resposta exigida por Gaia não pode ser a de uma tomada de poder, mas sim a de engajamentos que promovem possíveis capazes de interromper o sentimento de impotência. Como insiste Stengers, temos de nos recusar a nos colocar no lugar dos "nossos responsáveis", os que tomam decisões frequentemente impulsionados por alternativas infernais, e de deixar espaços abertos e livres para que se possa pensar, fórmula deleuziana da esquerda. Podemos, portanto, conectar o reclaim das feiticeiras e a máquina de guerra hacker, ambas formas criativas de resistir, de produzir uma experimentação política, ambas restituindo alguma possibilidade de ação coletiva, sob a recusa da captura. Stengers incita cientistas a buscarem laços com feiticeiras e hackers para, enfim, "aprender experimentar dispositivos que nos tornem capazes de viver tais provações sem cair na barbárie"53.

Se a origem da barbárie está nos cercamentos, na perda dos vínculos que constituem o comum, dos vínculos com a terra, então aquilo que é capaz de conectar todas as lutas contra a captura só pode ser aquilo capaz de reativar esses vínculos. Gaia é, no entanto, a Terra furiosa, com quem é preciso compor, sua intrusão evidencia que ciência e política não podem mais se separar. As ciências reivindicam novo papel - é preciso politizá-las, conectá-las a novas práticas - e a política, um novo lugar, devendo estender-se ao ambiente, aos não humanos, à Terra. A proposta cosmopolítica stengersiana revela-se também uma Gaia-política: não se trata de mover-se sobre o solo comum da Natureza, mas sim potencializar encontros, conectar práticas. Reativar aquilo que foi saqueado, o conhecimento que faz o comum, a comunidade - sem cair na ideia de um mundo comum unificado, mas sim na proliferação de vínculos. Não é por acaso que Stengers, num tom spinoziano, conclua o seu livro com um chamado à Alegria, alegria dos bons encontros, da potencialização dos corpos heterogêneos contra a ameaça triste do fim.

\section{CodA}

Se reativar/retomar é mesmo construir pontes e não simplesmente recuperar algo do passado, se é deixar-se potencializar por novas alianças, é preciso admitir que dentre essas práticas resistentes de que fala/escreve Stengers deveriam estar também, e especialmente, as dos povos indígenas. Se os cercamentos no início da era moderna coincidem com a erradicação das bruxas, não é menos verdade que eles coincidem com o longo processo de expropriação das terras indígenas, este que está na base da Conquista e que se perpetua até os dias de hoje na política dos Estados nacionais americanos. Com efeito, a caça às bruxas na Europa e a Conquista da América Conquista que foi tanto de territórios e recursos como de almas, não podemos

53 Ibidem, p. I42. 
esquecer - constituíram modos concomitantes de destruição do "bem comum”. A expulsão da terra visando à acumulação primitiva do capital ocorreu ao mesmo tempo na Europa e na América, e junto com os cercamentos vieram os cerceamentos de práticas de conhecimento e modos de existência singulares.

Haveria, como enfatizaram Starhawk e Federici, nas suas reflexões acima evocadas, uma associação direta entre a relação com a terra e as práticas de conhecimento, nas quais está fundada a magia. Com efeito, a expropriação das terras indígenas, processo que permanece em curso, veio sempre acompanhada de uma série de perseguições ideológicas, que passam pelo cerceamento das línguas e das práticas rituais ou ditas mágico-religiosas. Seja pela fé cristã, seja pela autoridade das ciências modernas, rituais e práticas xamânicas foram proibidos, descreditados e mesmo criminalizados. (Isso para não falar do canibalismo, que, como apontaram diversos estudos etnológicos, constitui um pilar importante das filosofias da diferença ameríndias.) Cerceamento e confinamento se inscrevem a um só tempo no plano do território e do conhecimento - e essa realidade mantém-se até os dias de hoje, por exemplo, no Brasil, onde órgãos indigenistas estatais e missões religiosas continuam exercendo atos etnocidas (para não dizer genocidas), no mais das vezes associados a ações ecocidas ${ }^{54}$. Tudo isso faz dos povos indígenas em pleno século XXI - tanto aqueles que convivem com o "mundo dos brancos" há tempos (como os Guarani e os Tupinambá) como aqueles que lutam para não estabelecer o "contato oficial" (como os Piripkura e os Hi-Merimã) - como resistentes no mais do termo. Tais as ativistas neopagãs, evocadas por Stengers, os povos indígenas poderiam nos dar lições de como nos proteger, de como resistir nessa era reconhecida como Antropoceno ou Capitaloceno, tempo de catástrofes e de escancaramento das "feitiçarias do capitalismo". No reclaim de Starhawk, assim como nas retomadas de terras dos povos indígenas, fenômeno que responde a séculos de expropriação, o que está em jogo é a relação irrefutável entre terra e magia, entre o acesso a um "bem comum" - a capacidade de pensar e agir em conjunto - e a animação dos existentes, entre o material e o imaterial, entre a espiritualidade e a política.

Essa forte relação entre reativar a magia e retomar a terra é o que faz conectar lutas indígenas e lutas modernas (ou urbanas). Como profere Davi Kopenawa em A queda do céu, sem os xamãs yanomami - estes que podem ver os xapiripë, ancestrais animais, imagens da terra-floresta - o céu vai desabar, e as consequências serão vividas por todos os habitantes do planeta, inclusive os napë (estrangeiros, brancos), responsáveis, aliás, por muitas dessas catástrofes. Nesse alerta reside seu "manifesto cosmopolítico", esse discurso político dotado de forte conteúdo cosmológico e que vem direcionado aos napë, como bem o define Albert 55 . Se os não indígenas não se dispuserem a aprender com as práticas e as lutas dos Yanomami - o que

54 Para uma discussão sobre a associação entre etnocídio, genocídio e ecocídio na relação entre povos indígenas e o Estado brasileiro na Amazônia atual, ver: MOLINA, Luísa Pontes. Terra, luta, vida: autodemarcações indígenas e afirmação da diferença. Dissertação (Mestrado em Antropologia). Departamento de Antropologia, Universidade de Brasília, 20I7.

55 ALBERT, Bruce. Prólogo. In: KOPENAWA, Davi; ALBERT, Bruce. A queda do céu: palavras de um xamã yanomami, São Paulo: Companhia das Letras, 2015. 
inclui sua insistência na retomada do xamanismo e nos seus conceitos de urihi e hutukara, a "terra-floresta” - o mundo perecerá, o céu desabará. Em resposta a essa cataclismologia, que poderia ser posta em analogia com a "irrupção de Gaia”, Kopenawa incorre em um movimento de "desenfeitiçamento", protagonizado pelos xamãs yanomami e jamais dissociado da salvaguarda territorial, conquista inegável dos Yanomami. É na mesma direção que Danowski e Viveiros de Castro afirmam serem os povos indígenas "especialistas em fim de mundo" - isto é, resistentes por excelência nesse tempo de catástrofes, no qual a relação entre "nós” e o "mundo" é submetida a um intenso questionamento, que demanda a conexão entre diferentes modos de especulação $0^{56}$. Os povos indígenas poderiam, assim, nos ajudar a habitar o "tempo do fim", como o concebeu o filósofo Gunther Anders, mas desde que lutemos, junto com eles, contra o seu próprio fim, que lutemos contra a tal "narrativa épica" que nega a sua existência e que hoje, mais do que nunca, se materializa em violação de direitos e em genocídios. Desde que aprendamos também com suas artes da imanência e com suas técnicas de contratranscendência, isto é, com sua incessante crítica xamânica da economia política da mercadoria, como bem resumido mais uma vez por Albert57.

As lutas indígenas, que congregam a defesa da terras e de práticas como o xamanismo, podem ser efetivamente conectadas às lutas vividas no mundo não indígena supostamente "moderno" - as lutas dos diferentes usuários e praticantes contra a captura do "sistema feiticeiro" e em busca do restabelecimento de um "comum”. Em ambos os casos, vale insistir, lutas contra cercamentos a um só tempo da terra e do conhecimento. É nesse sentido que Stengers compreende a "reativação do animismo": como reativação/retomada, antes de tudo, de vínculos, de modos de produzir conexões e de resistir à imposição de uma ontologia unívoca e única, autoritária. Se parece impossível para aqueles que se reconheceram como modernos viver numa "sociedade contra o Estado" e "para a liberdade”, como a retratava Clastres, seria possível apostar na criação de interstícios que possam abrigar distintos modos de existência, novas formas de vida. É da conexão jamais unificante entre diferentes modos de reativação/retomada - diferentes modos de reativar/retomar o que foi silenciado ou o que vive sob ameaça constante - que uma criatividade política potente poderá emergir. Esta terá sido uma lição importante da filosofia de Isabelle Stengers, aqui fecundada de um sutil enviesamento americanista na busca por pensar formas de resistência e um outro sentido para o que costumamos chamar, desde a Grécia Antiga, de política.

56 DANOWSKI, Débora; VIVEIROS DE CASTRO, Eduardo, op. cit.

57 ALBERT, Bruce. O outro canibal e a queda do céu. In: ALBERT, B.; RAMOS, A. Pacificando o branco: cosmologias do contato no Norte-Amazônico. São Paulo: Ed. da Unesp, 2000. 


\title{
SOBRE O AUTOR
}

\author{
RENATO SZTUTMAN é mestre e doutor em \\ Antropologia Social pela USP, professor do \\ Departamento de Antropologia da USP e pesquisador \\ do Centro de Estudos Ameríndios (CEstA/USP) e do \\ Laboratório de Imagem e Som em Antropologia (Lisa/ \\ USP). \\ E-mail: rsztutman@usp.br
}

\section{REFERÊNCIAS BIBLIOGRÁFICAS}

ALARCON, Daniela Fernandes. O retorno da terra: as retomadas na aldeia tupinambá Serra do Padeiro, sul da Bahia. Dissertação (Mestrado em Ciências Sociais). Brasília: UnB, 2013.

ALBERT, Bruce. Temps du sang, temps des cendres: representation de la maladie, systeme rituel et espace politique chez les Yanomami du Sud-Est (Amazonie Brésilienne). Doctoral dissertation. Paris, Laboratoire d'Ethnologie et de Sociologie Comparative, I985.

. O outro canibal e a queda do céu. In: ALBERT, B.; RAMOS, A. Pacificando o branco: cosmologias do contato no Norte-Amazônico. São Paulo: Ed. da Unesp, 2000.

. Prólogo. In: KOPENAWA, Davi; ALBERT, Bruce. A queda do céu: palavras de um xamã yanomami, São Paulo: Companhia das Letras, 2015.

ANDUJAR, Claudia. A vulnerabilidade do ser. São Paulo: Cosac Naify, 2005.

BENSAUDE-VINCENT, Bernadette; STENGERS, Isabelle. Histoire de la chimie. Paris: La Découverte, I993. BRECHT, Bertolt. (I929). A peça didática de Baden Baden sobre o acordo. In: . Teatro completo. V. 3 . São Paulo: Paz e Terra, I988.

DE LA CADENA, Marisol. Earth beings: ecology of practice among andean worlds. Durham/London: Duke University Press, 2015.

CASSIN, Barbara. O efeito sofístico. Tradução de Ana Lúcia de Oliveira, Maria Cristina Franco Ferraz e Paulo Pinheiro. São Paulo: Ed. 34, 2005. (Coleção TRANS).

CHERTOK, Léon; STENGERS, Isabelle. L’hypnose: blessure narcisique. Paris: Les Empêcheurs de penser en rond, I999.

CLASTRES, Pierre. La societe contre l'état: recherches d'anthropologie politique. Paris: Seuil, I974. . (I980). Arqueologia da violência: pesquisas de antropologia política. São Paulo: Cosac Naify, 2004. DESCOLA, Philippe. Par delà nature et culture. Paris: Gallimard, 2005.

DANOWSKI, Débora; VIVEIROS DE CASTRO, Eduardo. Há mundo por vir? Ensaio sobre medos e fins. São Paulo: ISA; Florianópolis: Cultura e Barbárie, 20I4. DELEUZE, Gilles. Les intercesseurs. In: . Pourparlers. Paris: Eds. de Minuit, I990. ; GUATTARI, Félix. La machine de guerre: traité de nomadologie. In: DELEUZE, Gilles; GUATTARI, Félix. Mille plateaux: capitalisme et schizophrénie II. Paris: Eds. de Minuit, I980. . Mille plateaux: capitalisme e schizophrénie II. Paris: Ed. de Minuit, I980.

EVANS-PRITCHARD, E. E. (I936). Bruxaria, magia e oráculos entre os Azande. Rio de Janeiro: Zahar, 2005. FEDERICI, Silvia. Calibã e a bruxa: mulheres, corpo e acumulação primitiva. São Paulo: Ed. Elefante, 20I7. 
FAVRET-SAADA, Jeanne. Les mots, la mort, les sorts: la sorcellerie dans le Bocage. Paris: Gallimard, I977. . Désorceler. Paris: Ed. de l'Olivier, 2009.

GALLOIS, Dominique. O movimento na cosmologia waiãpi: criação, expansão e transformação do universo.

Tese (Doutorado em Antropologia Social). São Paulo, Universidade de São Paulo, I988.

GUATTARI, Félix. (I992). Caosmose: um novo paradigma estético. São Paulo: Ed. 34, 2008.

GELL, Alfred. Art and agency: an anthropological theory. Oxford: Clarendon Press, I998.

GOLDMAN, Marcio. A relação afroindígena. Cadernos de Campo, v. 23, n. 23, 20I4, p. 2I3-222.

. "Quinhentos anos de contato": por uma teoria etnográfica da (contra)mestiçagem. Mana, v. 2I, n. 3, 20I5.

GUARANI, Jera Giselda et al. Conversa com Jera Giselda. In: AZEVEDO, José Fernando (Org.). Nhanhomorimba: um panfleto esquiva. São Paulo: EAD/USP, 2017.

HACHE, Émilie. Starhawk, le rituel et la politique. In: CONGRES MARX INTERNATIONAL V - Section

Etudes Féministes Atelier 9: Féminismes, altermondialisme et utopies - Paris-Sorbonne et Nanterre $-3 / 6$ octobre 2007.

HARAWAY, Donna. Staying with the trouble: making kin in the Chtulucene. Durham: Duke Press, 2016.

HOLBRAAD, Martin. The power of powder: multiplicity and motion in the divinatory cosmology of Cuban

Ifá. In: HENARE, A.; HOLBRAAD, M.; WASTELL, Sari (Ed.). Thinking through things: theorizing artefacts ethnographically. London: Routledge, 2007.

KOPENAWA, Davi; ALBERT, Bruce. A queda do céu: palavras de um xamã yanomami. São Paulo: Companhia das Letras, 2015 .

LATOUR, Bruno. Petite refléxion sur le culte moderne des dieux faitiches. Paris: Les Empêcheurs de penser en rond, I993.

. Face à Gä̈a: huit conférences sur le nouveau regime climatique. Paris: La Découverte, 2015.

LÉVI-STRAUSS, Claude. La pensée sauvage. Paris: Plon, I962.

MOLINA, Luísa Pontes. Terra, luta, vida: autodemarcações indígenas e afirmação da diferença. Dissertação (Mestrado em Antropologia). Departamento de Antropologia, Universidade de Brasília, 2017.

MOORE, Jason M. Anthropocene or Capitalocene? Nature, history and the crisis of capitalism. Oakland:

PM Press, 2016.

NATHAN, Tobie; STENGERS, Isabelle. Médicins et sorciers. Paris: La Découverte, 2004.

PIGNARRE, Philippe; STENGERS, Isabelle. La sorcellerie capitaliste: pratiques de désenvoûtement. Paris:

La Découverte, 2005.

POVINELLI, Elizabeth. Geontologies: a requiem to late liberalism. Durham: Duke Press, 2016.

PRIGOGINE, Ilya; STENGERS, Isabelle. La nouvelle alliance: métamorphose de la science. Paris: Gallimard, I979.

STARHAWK. Dreaming the dark: magic, sex, and politics. Boston: Beacon Press, I982.

STARHAWK. Webs of power: notes from the global uprising. Gabriola Islands: New Societies Publisher, 2002.

STARHAWK. Rêver l'obscure: femmes, magie et politique. Paris: Les Empêcheurs de penser en ronde/Le Seuil, 2003.

STENGERS, Isabelle. L’invention des sciences modernes. Paris: La Découverte, I993. . Cosmopolitiques I. Paris : Éditions la Découverte, I997. . Cosmopolitiques II. Paris : Éditions la Découverte, I997. . Pour en finir avec la tolérance. In: . Cosmopolitiques II. Paris: La Découverte, I997. . Penser avec Whiteahead: une libre et sauvage création de concepts. Paris: Seuil, 2002a . L'hypnose entre magie et science. Paris: Les Empêcheurs de penser en rond/Seuil, 2002b. 
. Préface à l'édition française. In: STARHAWK. Rêver l'obscure: femmes, magie et politique. Paris: Les Empêcheurs de penser en ronde/Le Seuil, 2003.

. La Vierge et le Neutrino: les scientifiques dans la tourmente. Paris: La Découverte, 2006.

. La proposition cosmopolitique. In: LOLIVE, Jacques; SOUBEYRAN, Olivier (Ed.). L'émergence des cosmopolitiques. Paris: La Découverte, 2007.

. Experimenting with refrains: subjectivity and the challenge of escaping modern dualism. Subjectivity, v. 22, n. I, 2008.

. Au temps des catastrophes: résister à la barbarie qui vient. Paris: La Découverte, 2009.

. Une autre science est possible! Manifeste pour un relentissement des sciences. Paris: La Découverte, 2013.

. Gaia, the urgency to think (and feel). In: COLÓQUIO INTERNACIONAL OS MIL NOMES DE GAIA: DO ANTROPOCENO À IDADE DA TERRA. Casa de Rui Barbosa, Rio de Janeiro. Departamento de Filosofia/PPGAS Museu Nacional/UFRJ. I5 a I9 set. 20I4. Disponível: <https://osmilnomesdegaia.files. wordpress.com/20I4/II/isabelle-stengers.pdf $>$. Acesso em: 26 ago. $20 I 7$.

. Reativar o animismo. Tradução Jamille Pinheiro Dias. Belo Horizonte: Chão de Feira, 20I7. (Caderno de Leituras n. 62).

STRATHERN, Marilyn. Partial connections. Lanham: AltaMira Press, I99I.

. The gender of the gift: problems with women and problems with society in Melanesia. Berkeley: University of California Press, I988.

. Retomar a Terra, ou como resistir no Antropoceno - projeto Antropocenas. I7 out. 20I7. Buala

- Plataforma que atua sobre questões pós-coloniais nas áreas da cultura, comunicação, arte e educação.

Disponível em: <www.buala.org/pt/a-ler/retomar-a-terra-ou-como-resistir-no-antropoceno-projeto -antropocenas $>$. Acesso em: 28 ago. 2017.

VANZOLINI, Marina. A flecha do ciúme: o parentesco e seu avesso segundo os Aweti. São Paulo: Terceiro Nome.

VERA, Stela. Se não tiver reza o mundo vai acabar. Depoimento recolhido e transcrito por Lauriene Seraguza (doutoranda em Antropologia Social pela Universidade de São Paulo) e traduzido em conjunto com Jacy Caris Duarte Vera (licenciada em Ciências da Natureza, professora Ava Guarani), em fevereiro de 2016. Povos Indígenas no Brasil. Disponível em: <https://pib.socioambiental.org/pt/c/no-brasil-atual/ narrativas-indigenas/se-nao-tiver-reza-o-mundo-vai-acabar >. Acesso em: 26 ago. 2017.

VIVEIROS DE CASTRO, Eduardo. Os involuntários da pátria: elogio do subdesenvolvimento. Belo Horizonte: Chão da Feira, 2016.

ZOURABICHVILLI, François. Deleuze e o possível (sobre o involuntarismo na política). In: ALliez, É. (Org.). Gilles Deleuze: uma vida filosófica. São Paulo: Ed. 34, 2000. 